\title{
Talons Cusp: A Report of Seven Cases and Review of Literature
}

${ }^{1} \mathrm{MB}$ Radhika, ${ }^{2} \mathrm{~K}$ Paremala, ${ }^{3} \mathrm{M}$ Sudhakara, ${ }^{4} \mathrm{M}$ Soumya

\begin{abstract}
Talon cusp is a well-delineated additional cusp which is located on the surface of an anterior tooth. Histologically it is composed of normal enamel, dentin and a pulp tissue. It is been classified into various types based on its extension and shape of the cusp. This anomaly generally poses problems for the patient in terms of esthetics, caries control and occlusal accommodation. Seven new cases of talon cusp with different clinical presentations are being presented along with approved diagnostic criteria.
\end{abstract}

Keywords: Talon cusp, Eagle's talon, Dental anomaly, Anterior teeth, Diagnostic criteria, Mohr's syndrome.

How to cite this article: Radhika MB, Paremala K, Sudhakara M, Soumya M. Talons Cusp: A Report of Seven Cases and Review of Literature. World J Dent 2014;5(1):76-79.

Source of support: Nil

Conflict of interest: None

\section{INTRODUCTION}

Talon cusp is a morphological developmental anomaly. It is a cusp like projection from the cingulum of maxillary/ mandibular anterior teeth, resembling an eagle's talon. ${ }^{1-3}$ It generally extends lingually or incisally which can be encountered in primary ${ }^{3}$ and secondary dentition. ${ }^{1,2}$ More than 50 cases of talon cusp have been reported in the secondary or succedenous dentition. The aim of this paper is to add seven more cases presenting in different forms and in addition, review the diagnostic criteria and literature.

\section{Criteria and Review of Literature}

The first report of talon cusp was made by WH Mitchell almost a century ago in $1892,{ }^{1,4}$ since then, depending on the clinicians' nomenclature various cases have been reported under the names of prominent cingulum, lingual tubercle, tendency toward talon cusp, occlusal anomalous tubercle, supernumerary cusp, talonism and talon cusp. ${ }^{5}$ Mader (1981) proposed that talon cusp is an anomalous cusp of successional incisor teeth. ${ }^{1,2}$ Henderson reported cases of

${ }^{1}$ Professor and Head, ${ }^{2,3}$ Reader, ${ }^{4}$ Senior Lecturer

${ }^{1-4}$ Department of Oral Pathology, Krishnadevaraya College of Dental Sciences, Bengaluru, Karnataka, India

Corresponding Author: M Sudhakara, Reader, Department of Oral Pathology, Krishnadevaraya College of Dental Sciences Bengaluru, Karnataka, India, e-mail: sudhakarmop@gmail.com talon cusp in primary dentition, ${ }^{4}$ followed by reports of Mass et al and Davis et al establishing the fact of occurrence of talon cusp in deciduous dentition. Hence, Davis and Brook suggested that the definition of talon cusp is best compiled as-An additional cusp that projects from the lingual surface of primary or secondary teeth, is morphologically well delineated and extends at least half the distance from the cementoenamel junction to the incisal edge. ${ }^{6}$

Hattab et al have classified talon cusp on the basis of degree and extent of cusp formation in 1995 into three groups: ${ }^{7,8}$

Type 1: Talon has an additional cusp that projects from the palatal surface of an anterior tooth and extends at least one half the distance from the cementoenamel junction to the incisal edge.

Type 2: Semi-talon has an additional cusp $1 \mathrm{~mm}$ or more in length but extending less than one half the distance from the cementoenamel junction to the incisal edge.

Type 3: Trace talon manifests as enlarged and prominent cingula and their variations.

A carefully framed criteria helps in establishing the true incidence and prevalence rates.

All the present cases completely satisfy the above criteria.

Using these above criteria, Chawla et al have shown that the incidence rate of talon cusp in Indian children is about $7.7 \%$.

Mitchell reported the first case of talon cusp in 1892 in a woman who showed a horn like cingulum on the left maxillary central incisor. ${ }^{1,2,4}$ Schulze referred to the anomaly as a very high cusp of ' $\mathrm{T}$ ' or ' $\mathrm{Y}$ ' form. Finally, Mellor and Ripa coined the term 'Talon cusp' in 1970. ${ }^{9}$ Ratanen described a 16-year-old girl having talon cusp on all the maxillary anterior teeth. He stated that the occurrence of several talon cusps in the upper jaw is a form of hyperproductivity of anterior ends of dental lamina. ${ }^{10}$ Goldstein and Medina in 1974 published detailed case of Mohr syndrome, in which the patients presented talon cusp with dental defects. ${ }^{11}$

Henderson first described a talon cusp in a deciduous dentition in1977. ${ }^{3}$ Mader (1981) reported three cases of talon cusp along with the presence of mesiodens in one case. ${ }^{4}$ 
Natkin et al (1983) reported a case of talon cusp with other odontogenic abnormalities. In the same year, Chawla, Tewari and Gopalkrishna reported the occurrence of talon cusp in permanent teeth as $4.2 \%$ in central incisors, $2.11 \%$ in lateral incisors and $1.2 \%$ in canines after evaluating around 5633 school children aged about 10 to 16 years. In $1985,{ }^{12}$ Davis and Brook added twenty more cases of talon cusp. ${ }^{6}$ In 1986 Chen et al added six more cases in primary teeth, stating that the talon may occur as frequently in primary teeth as in the case of the permanent teeth. ${ }^{3}$ Jowhari et al published a case of facial talon in 1992 followed by another case of facial talon reported by Albott PV in 1998. ${ }^{5}$ Chaudari and Gosavi reported two cases in1993 and stated that the occurrence of talon cusp may not be so rare. ${ }^{4}$ Hattab, Yassin and Al-Nimri added seven more cases of talon on permanent teeth along with a classification of talon cusp. ${ }^{7}$ Sarkar S, Misra J and Das $\mathrm{G}$ (1999) reported a case of talon cusp, in which members of a family showed presence of multiple talons. They stated that genetics had a role to play in the formation of talon cusp. ${ }^{4}$ In 2002, Seares, Simone and Marion reported a case of bilateral talon and stressed on a conservative and timely management of teeth affected by talon cusp. ${ }^{8}$

\section{CASE REPORTS (TABLE 1)}

\section{Case 1}

A 10-year-old girl reported with pain in upper left molar region. Oral examination revealed mixed dentition with permanent maxillary right lateral incisor having a talon cusp. The patient was unaware of its existence and had no complaints regarding it. Talon cusp was placed close to the lingual surface of the tooth giving rise to a groove formation (Fig. 1).

\section{Case 2}

An 11-year-old girl reported to the clinic with pain and decay in lower molars. On oral examination, a talon cusp

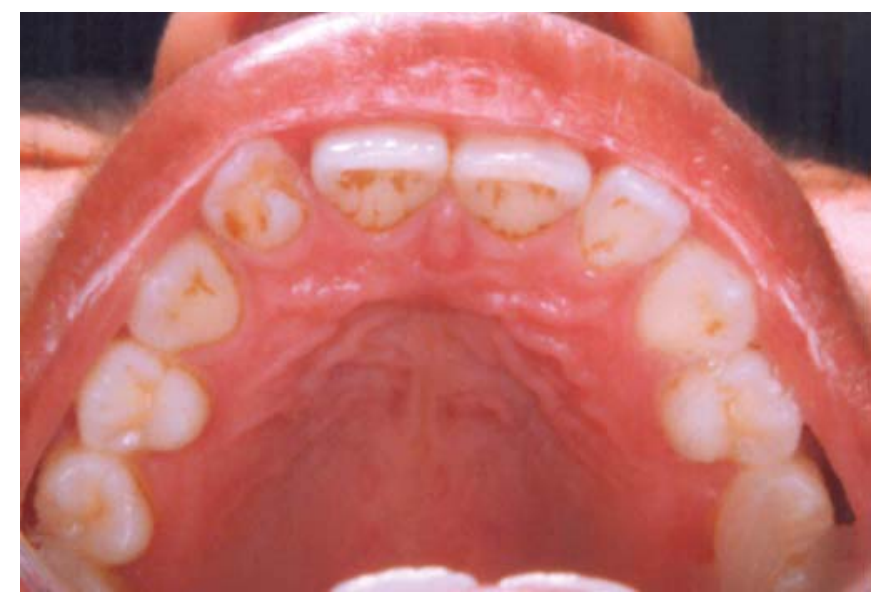

Fig. 1: Hattab et al type 3 talons cusp as seen in our case 1 was noticed in relation with permanent maxillary right lateral incisor which was asymptomatic (Fig. 2).

\section{Case 3}

A male, 22 years of age reported to the clinic for oral prophylaxis. A talon cusp was seen in relation with permanent maxillary left lateral incisor. On oral inspection, there was no occlusal disharmony or esthetic complaints (Fig. 3).

\section{Case 4}

A 18-year-old male came to clinic for a restoration. Oral examination revealed presence of talon cusp in relation to permanent maxillary left lateral incisor and a Leongs premolar on permanent maxillary right first premolar. He was unaware of the above findings as they were asymptomatic.

\section{Case 5}

A 22-year-old female came for orthodontic treatment to the clinic. Talon cusp was seen bilaterally seen on permanent maxillary right lateral incisor and permanent maxillary left lateral incisor. Deep furrow and groove was seen in relation with the talon's cusp which were susceptible to caries (Fig. 4).

\section{Case 6}

A dental student, 20-year-old female came and reported a talon cusp on permanent maxillary right lateral incisor. She became aware of it after they were taught about developmental anomalies related with teeth (Fig. 5).

\section{Case 7}

A 22-year-old girl came for oral prophylaxis. Talon cusp was revealed on permanent maxillary left lateral incisor. On oral examination, she had no complaints about the tooth. Tooth rotation was seen in relation to it, making the talon's cusp appear as a facial talon.

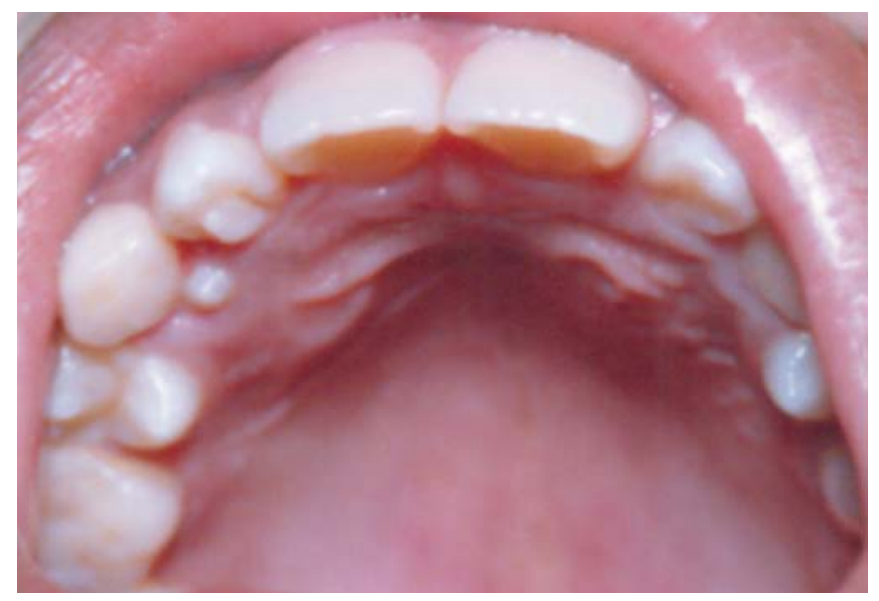

Fig. 2: Hattab et al type 2 talons cusp seen on 12 in case 2 


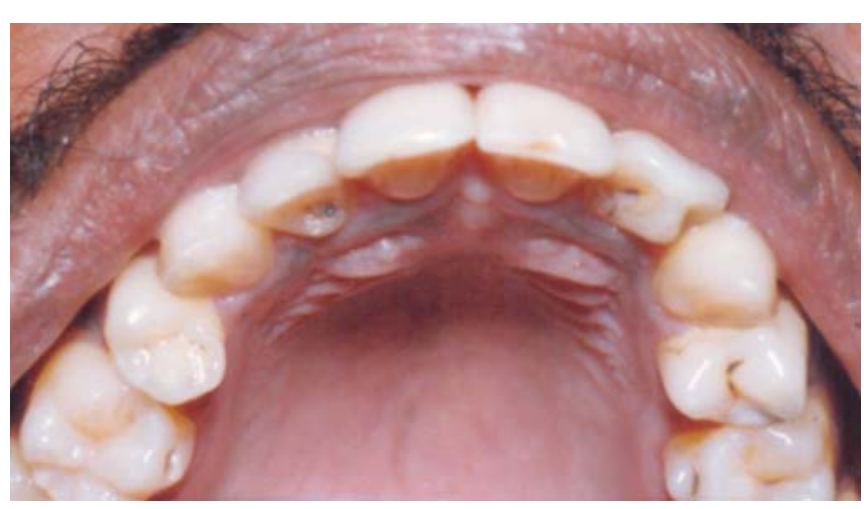

Fig. 3: Hattab et al type 1 talons cusp clearly seen in case 3

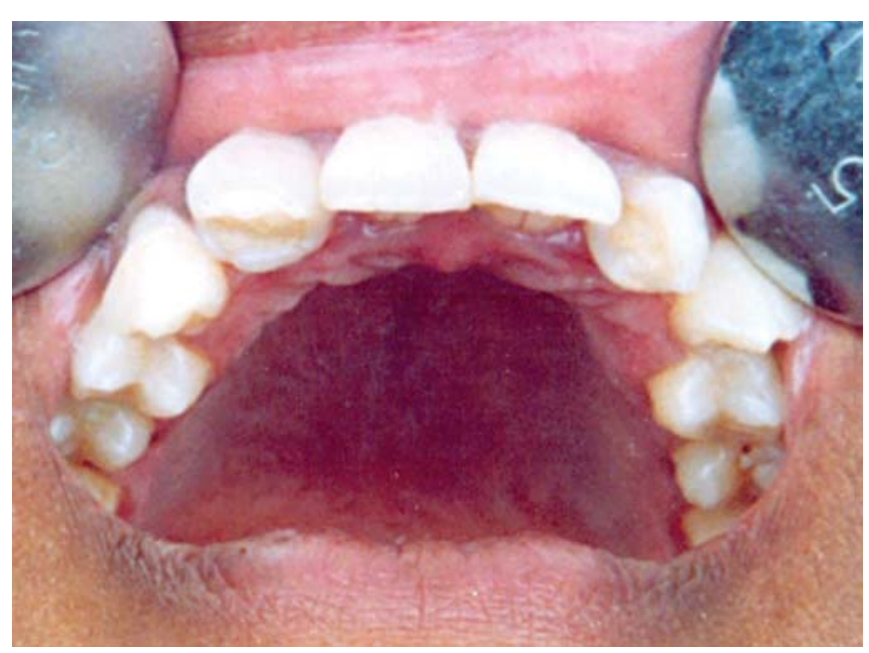

Fig. 4: H-shape talons cusp presented bilaterally in case 5

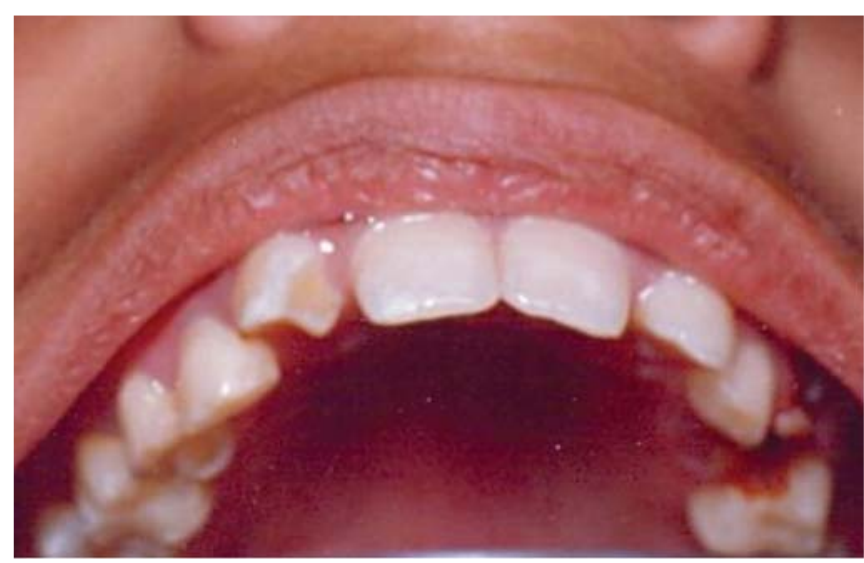

Fig. 5: T-shape talons cusp seen in case 6

\section{DISCUSSION}

Talon's cusp is a dental anomaly frequently involving maxillary permanent incisors and rarely mandibular incisors is said to be of rare occurrence in the general population. Both males and females are affected, as seen in this report. Talon cusp is characterized by a well-demarcated additional cusp on the lingual surface of the anterior teeth extending from cementoenamel junction to incisal edge. Depending on the size and type it involves enamel, dentin, cementum and pulp. Depending on the clinician's nomenclature various cases have been reported as-prominent cingulum, lingual tubercle, tendency toward talon cusp formation, talonism, talon cusp. Mader suggested that only those anomalous cusp of succedenuous incisor teeth that are morphologically well demarcated and prominently project lingually from the cementoenamel junction and incisal edge to at least half the distance of the tooth be called as a talon cusp. In the present report all the cases satisfy the above mentioned criteria. All the patients showed well developed and demarcated talon cusp on permanent teeth forming a three- pronged pattern. All the cases showed type 1 talon of Hattab et al's classification depicting true talon cusp formation. This dental anomaly of the anterior teeth in primary and secondary dentition is said to be rare in the general population. Observations indicate that the prevalence rate may be higher. Natkin et al attributes the rarity of the anomaly to failure of reporting in the past. The prevalence rate as reported is $0.17 \% .^{3}$ and a incidence rate of $7.7 \%$ in Indian school children in $1983 .{ }^{6,11}$ Chen et al have stated that incidence of talon cusp is high in case of Chinese origin children. Extensive prevalence studies have not been done but the estimates suggest a frequency of 0.17 to $5.2 \%{ }^{3}$ Review of English literature between 1970 and 1995 shows $77 \%$ of cases occur in secondary dentition, with $94 \%$ of these involve maxillary teeth. Sixtyfive percent of cases occur in males of maxillary lateral incisors followed by maxillary central incisor. The use of well framed diagnostic criteria and regular reporting will give the true prevalence rate of talon cusp. ${ }^{8}$ Talon cusp may arise as an isolated finding or may be associated with other somatic and odontogenic anomalies. ${ }^{3,6}$ The accessory cusp may arise as a part of syndrome also. ${ }^{1-3,12}$ It is seen to occur

Table 1: Clinical details of all the cases

\begin{tabular}{lllll}
\hline $\begin{array}{l}\text { Case } \\
\text { no. }\end{array}$ & Age (yrs) and sex & Presenting chief complaint & $\begin{array}{l}\text { Tooth involved } \\
\text { (FDI) }\end{array}$ & $\begin{array}{l}\text { Symptoms associated } \\
\text { with the talon }\end{array}$ \\
\hline 1 & $10 \mathrm{yrs} / \mathrm{F}$ & Pain in upper left molar region & 11 & $\begin{array}{l}\text { Asymptomatic with groove } \\
\text { formation }\end{array}$ \\
& & Pain and decay in lower molars & 12 & Asymptomatic \\
3 & $11 \mathrm{yrs} / \mathrm{F}$ & Oral prophylaxis & 22 & Asymptomatic \\
4 & $22 \mathrm{yrs} / \mathrm{M}$ & Restoration & 22 and14 & Asymptomatic \\
5 & $18 \mathrm{yrs} / \mathrm{M}$ & Orthodontic treatment & 12 and 22 & Deep furrow and grooves \\
6 & $22 \mathrm{yrs} / \mathrm{F}$ & Aware of the anomaly & 12 & Asymptomatic \\
7 & $20 \mathrm{yrs} / \mathrm{F}$ & Oral prophylaxis & 22 & Asymptomatic \\
\hline
\end{tabular}

F: Female; M: Male 
in both males and females, the presentation being unilateral or bilateral. ${ }^{8}$ The talon formation is seen more frequently on the lingual surface of maxillary anteriors than on mandibular anteriors or canines. All the cases reported in the present study shows the occurrence of talon on maxillary lateral incisors. Facial or labial talon have also been reported. 5,13 A suggestion to additional labial or lingual surface to the definition when the talon cusp occurs as an isolated finding. It generally presents no serious problem to the patient or to the clinician. It might sometimes cause interference with occlusion, attrition of opponent tooth and pain in periodontal ligament which are secondary to traumatic occlusion. ${ }^{1,2,6}$ The form of talon cusp might vary from case to case. In some instances the tip of the talon cusp may stand away from the rest of the crown increasing the labiolingual dimension. Case 2 is a typical example of this type of presentation. In other cases, there is a full surface opposition of talon cusp to the lingual surface of the tooth. This results in a fissure between the cusp and the tooth, which is susceptible to caries and might lead to pulpal or periopulpal pathology, more so if the groove extends on the radicular portion. ${ }^{6}$ This form of presentation was seen more commonly in this study in case 1 and 5. Talon cusp might be a source of irritation to the tongue during speech and mastication. Some cases may be esthetically not acceptable either because of inclination or rotation of the tooth bearing the talon. This is also true in cases of facial talon's cusp. ${ }^{13,14}$ Our present case 5 showed similar problems with a prominent talon formation on a rotated tooth. Not very infrequently the talon cusp is seen to occur with other dental or systemic manifestations. There are reports of talon's cusp occurring concurrently with a peg lateral and mesiodens. Natkin et al have showed the presence of talon with ectopically placed canine and complex odontome. ${ }^{3}$ A leong's premolar was seen to be associated with talon's cusp in case 4 . Case 5 showed a bilateral occurrence but without systemic manifestations. Mohr's syndrome or Orofacial digital II syndrome is inherited as a autosomal recessive trait, exhibits features of talonism along with other oral manifestations like polynodular tongue, midline cleft, high arched palate, hypertrophy of frenum, hypertaurodontism and supernumerary teeth/cusp. Talon cusp is seen as a part of Rubinstein Taybe and also Sturge Weber syndrome. ${ }^{12}$ Sarkar et al have shown the presence of talon in many members of a family, showing a genetic or hereditary pattern. ${ }^{4}$ However, none of the cases in the present study were syndrome related. The treatment of talon cusp, whether conservative or radical has to be cautiously chosen depending on the accessory cusp shape, size, presentation, location and tooth affected. The above procedure should be undertaken only after a mandatory radiographic evaluation. In some cases it is not necessary to perform any treatment, as it was clearly seen in case 1 . A conservative treatment protocol was used to treat cases of 2, 3, 4 and 6, 7. In case 5, a more radical approach was used as pulpal involvement was seen bilaterally. The etiology of this anomaly has remained fairly elusive. Hyperactivity of the anterior region of dental lamina, ${ }^{6,10}$ mutational dysmorphogenesis, odontogenic abnormalities and genetic factors are some of the causes held responsible for the formation of talon cusp. Different theories have been put forth to explain this anomaly, and it is suggested that this condition has a multifactorial etiology including both environmental and genetic factors. ${ }^{4,8}$

\section{CONCLUSION}

This report of seven cases, highlights the variations in clinical presentation and clinical consequences of talon cusp. Stress is laid upon the use of accepted, well framed criteria, which will help in early and correct diagnosis. This will minimize problems like caries, periapical pathology, periodontal diseases and occlusal disharmony. ${ }^{1,2,6,11}$ Use of criteria and regular reporting will help in finding the existing prevalence rate of talon cusp.

We hope the present collection of cases acts as a basis for further studies to throw light on the etiology and associations of the talon cusp. In addition, it will also help in finding the true incidence rate of anomaly.

\section{REFERENCES}

1. Mader CL. Mandibular talon cusp. J Am Dent Assoc 1982;105: 651-653.

2. Carson L, Mader CL. Talon cusp. JADA 1981;103:244-246.

3. Ren-Jye-Chen. Talon cusp in primary dentition. Oral Surg Oral Med Oral Pathol 1986;62:67-72.

4. Sarkar S, Misra J, Das G. Talon cusp- heredity origin—a case report. J Indian Soc Pedo Prev Dent 1999;17(4):126-128.

5. Abbott PV. Labial and Palatal 'Talon cusps' on the same tooth-a case report. Oral Surg Oral Med Oral Pathol Oral Radiol Endod 1998;85:726-730.

6. Davis PJ, Brook AH. The presentation of talon cusp: diagnosis, clinical features, association and possible etiology. Brit Dent J 1986;160:84-88.

7. Habab FN, Yassin OM, Al Nimri KS. Talon cusp in permanent dentition associated with other dental anomalies: Review of literature and reports of seven cases. J Dent Child 1996;63: 368-376.

8. Soares AB, de Araujo JJ, de Sousa SMG. Bilateral talon cusp: case report. Quintessence International 2002;2:90-93.

9. Mellor JK, Ripa LW. Talon cusp: a clinically significant anomaly. Oral Surg Oral Med Oral Patho1970;29:225-228.

10. Rantanen AV. Talon cusp. Oral Surg Oral Med Oral Pathol 1971;32:398-400.

11. Goldstein E. Mohr syndrome or oral- facial-digital syndrome: report of two cases. JADA 1974;89:377-382.

12. Chawla HS, Tewary A, Gopalakrishnan NS. Talon cusp: a prevalence study. J Indian Soc Pedod Prev Dent 1983;1:28-34.

13. Jowharji N, Noonan RG, et al. An unusual case of dental anomalies: A 'facial' talon cusp. J Dent Child 1992;59: 156-158.

14. Tsutsumi T, Oguchi H, et al. Labial talon cusp in a child with incontinentia pigmenti achromians_-case report. Pediatr Dent 1991;13:236-237. 